\title{
Some Conceptual Issues of Modern Geopolitics: A view from Russia
}

\author{
Oleg N. Yanitsky \\ Doctor of Philosophy, Professor, Chief Researcher, \\ The Federal Center of Theoretical and Applied Sociology of the Russian academy of sciences.
}

\begin{abstract}
Drawing on theoretical works in geopolitics and sociology as well as on my own works in these fields, the author came to the following conclusions. First, human history consists of the periods of sustainability and transitions. Second, the history shows that the scientific and technological innovations including that of in the social technologies have usually been the drivers of geopolitical transformations. Third, we are now living in a complex and mobile sociobiotechnosphere (hereafter the SBT-system). Fourth, such complex system is needed in interdisciplinary approach. Fifth, a cornerstone of this system existence is the variety of metabolic processes including social ones. Sixth, the contradictions between various attitudes and models of transition process toward the Fourth industrial revolution are the main impediments for a smooth transition period. Seventh, an adequate concept of our living environment is a necessary precondition for the successful transition period. Eighth, the existed social institutions are lag behind the pace and time rhythms of ongoing transformations. Ninth, the decision-making acts should be replaced by an interrupted process going one step forward in comparison with the transformations of any SBT-system. Tenth, the existing concept of global social ecosystem should be reconsidered.
\end{abstract}

Keywords: ecosystem, environment, geopolitics, globalization, institutions, internet, metabolism, mobility, SBT-system, transition period, Russia

\section{INTRODUCTION}

The geopolitics as a science and practice is developing together with the evolution of forms and methods of global practices of humanity, be it local, regional or global. If we compare the initial definition of the geopolitics as an opposition between land power and sea power given by Sir H. Mackinder we'll see the distance which this discipline has passed. Recently, we are witnessing the qualitatively new stage of this complex discipline shaping by the transition from traditional to post-modern society, or more exactly from the Second and Third Industrial revolution to the Fourth one. But the matter is that in this transition period a pace of political, scientific and social transformations were not the same.

As human history shows, the scientific and technological innovations including that of in the social technologies have usually been the drivers of geopolitical transformations. And usually the inventions of new forms of mode of production immediately realized in a military sphere have been such drivers. Then, the further the more a politics as socially-constructed forms of human activity (in the widest sense of the word) came to the fore front. The enormously grown role of mass-media is the best example here. At the same time an industrial sphere has become a subaltern element guided by global market, consumer ideology and political facts constructed by the media.

A geopolitical function of a religion and ideology systems are important as well but it's a specific theme that beyond the frames of this article. Nevertheless, it should be mentioned that 
this very systems were first that pointed out that cosmic immaterial systems are the important part and guide of the geopolitics of human beings.

A current geopolitics as the science has at least three sets of unresolved problems. The first is it a 'real-politik' or a symbolic practice? The second is it totally guided by global market or by particular interest groups (i.e. global stakeholders) and individual political leaders? And the third one, what is the realm of current geopolitics: the Biosphere at hands, so-called Anthropocene or the cosmic space without of any definite space-time borders?

One should take into account that recently any concept of global scale is permanently oscillating between solid facts and empirically untested hypotheses. I don't neglect the very phenomenon of building the hypotheses I only stated that the scientists stepping on this shaky ground are becoming the prophets and oracles.

\section{Some lessons from recent transition period}

In this section I don't intend to analyze the geopolitical concepts as such because the old ones aren't fit to current times and the new one are only emerging. I would rely upon some international research projects aimed at the revealing of major trends and challenges of current transition period initiated by current transition towards an information society (Castells, 1996, 2004). It's significant that they were and still are of global scale and long-term in character, implemented by interdisciplinary teams and aimed at comprehension of the main features of transition period towards this kind of society. To name this period as the postmodern is too general. Therefore I'll use the term of the STR-4 though the participants of all three projects escaped to analyze this period as expansion of modern capitalism into the cosmic sphere.

It's rather indicative that the US scientists (and namely J. Forrester from the MIT, world-known specialist in global dynamics) initially being the initiators of this project later handled it in the hands of European consortium 'The Club of Rome' (the cumulative results of its half-a-century reports see in: Von Weizsäcker and Wijkman, 2018). It's characteristic as well, that the projects aimed at the saving of natural ecosystems are mainly concentrated in the EU and the Eastern Asia.

The focal points of the above three projects had been the threats of the planet overpopulation, a grooving deficit of resources (first of all, of energy and drinking water) and various risks from shrinking of global labor market, mass involuntary migration, poverty and other social 'bads', natural disasters and climate-induces changes, biodiversity losses to intergovernmental or global conflicts, cyberattacks and wars.

European scientists focused their project on two directions: a land use in the times of agricultural and industrial modes of production as well as on the social metabolic processes (Fisher-Kowalski, 1997; Fisher-Kowalski and Haberl, 2007; Haberl et al., 2016). It seems to me that the studies of all types of metabolic processes ranging from that of in the biosphere turnover and to a social metabolism as such because this process was not investigated in Russia at all. The other side of the same coin is a harmful impact on human health of nearly total chemicalization of food-staffs, detergents and other things of peoples' everyday use.

\section{Emergence of global socio-biotechnical systems}

The global market, shaping the all-embracing informational network, growing mobility of resources, people and goods and a lot of other interactions and various metabolic processes of local, regional and global scale led to shaping of the socio-biotechnical systems of various scale. 
Accordingly very slow but inevitably a realm of interdisciplinary research-and-developments area is shaping and widening. Even social scientists begin to realize that a human being as such is a very complicated multifunctional and therefore 'interdisciplinary creature' full of permanent metabolic processes of various scale, character and results.

Thus, neither theoretically nor practically the separation of society, nature and technical systems is methodologically and theoretically wrong. This fact doesn't neglect an existence and development of particular disciplines and their collaboration. But the forming of a 'single science' as F. Engels had predicted is the ongoing trend. More than that, such collaboration is necessary resource for the movement ahead especially in the transition period in question.

It's clear that the R\&D of such integrated systems requires appropriate methodology and instruments for getting necessary data. It's indicative that the most progress on this way has been achieved by those sciences and practices that dealing with technically-grounded complex systems like, for example, an architecture and town planning. Less but very impressive interdisciplinary studies and practical results have been achieved in the theoretical and practical medicine, plant-growing and livestock farming and in military sciences and developments.

As concerns to geosphere or the living space of humanity, including the mantle, lithosphere and the cosmic space a task of the interdisciplinary approach and decision-making is becoming much more complicated. The Vl. Vernadsky's concept of the biosphere is in essence a biochemical one whereas we are now urgently needed in the development of workable model of global socio-biotechnical system.

This task is much more difficult, in particular for the reason of almost zero mutual understanding between the scientists and scholars. In any case, the biosphere concept is not applicable to resolving of such extremely complicated task as the means of regulation of the biosphere as Russian biologists suggested (Yablokov et al., 2015). The biochemical presentation of the biosphere turnover as a closed circle 'producents-consumentsreducents' is not applicable to the global SBT-system in particular that such turnover in such systems is qualitatively different, much more complicated and may have a variety of temporhythms of its functioning and transformation.

And so I consider the geopolitics as a very efficient interdisciplinary science and effective mechanism for an establishment of such mutual understanding and practical collaboration on its any level, from local to global ones.

Finally, one should take into account that every SBT-system has its own regularities, specificity, tempo-rhythms of the functioning and development or conversely of destruction, and so on. It means that the methods and instruments of their studies are varied as well. If we are dealing with a cell or a particular living organism it's one thing but if the subject matter of our interest is a global sociobiotechnosphere it is quite another case that requires appropriate methods and instruments. And accordingly, a great amount of various resources. In any case, a particular SBT-system is always has a very complicated system of direct and feedback ties, links and communications.

\section{Geopolitics in a mobile world}

On the margin between the XIX and XX centuries when the concept of geopolitics began to shape our world had been relatively stable because the margins between the continents had been unmovable and economic-and-political map of the world had been shaped seemed for 
years. But after 20-25 years later the European subcontinent has become in motion. And in the run of the WWI and the WWII and many civil wars and national-liberation movements between and after them, until the Soviet Union decay in the end of the XX century our world became movable.

It means that the concept of global geopolitics as the struggle between the marine and the land states has become obsolescent. Since the Yalta's Summit (in the February 1945) the world division between the Great Powers seems stable, in essence the start of permanent re-division of the world political map began. At the end of XX century it became clear that global community is needed in a more flexible system of world, national and local institutions capable to meet coming challenges. That is, in a more flexible concept of global geopolitics.

Since the United Nations Organization and its divisions is a cornerstone of the world order, its member-states found out the palliative decision: not to touch this global institution and simultaneously to create more mobile social institutions like the European Union as well as to produce ad hoc institutions for the resolving permanently emerging tensions, conflicts and local wars. For example, it may be endless talks, temporary agreements, roadmaps or the 'frozen conflicts.'

With the coming of the STR-4 and shaping the common 'internet galaxy' the situation has changed qualitatively. The key issues are as follows. First, all countries and their inhabitants are under giant 'informational hat.' Second, the speed and processes of diversification are so high and differently directed that the UN and its committees are not capable even to collect relevant information concerning a particular conflict or disaster. Third, it leads to more and more unbalanced political decisions that, in turn signifies that the situation in situ has already changed. Fourth, as a result, the critical situation is emerging that, in turn needs of quite another decisions for example the mediators for making an armistice or the 'Doctors without Borders', etc. Fifth and is the most important: the decision-makers have to be capable to take into account a variety of metabolic transformations although each of them has its own spacetime dimension and side-effects.

\section{Towards what kind of world we are moving?}

First, due to the 'global information hat' we are now living in a united world. The 'power of the weakness' principle means in particular, that any agent in the cosmic space may be potentially threatening to any of us. That is, we are living in the world of all-embracing and all-penetrating risk and should be well-prepared to it.

Second, the existed geopolitical concepts based on dichotomy principles like 'here and there', 'we and they,' 'the front and the rear', etc. have to become obsolescent and should be replaced by a universal concept of peaceful and military activity of humans. In our times there is no principled difference between war and peace.

Third, simultaneously we are entering into a very mobile and compressed world. Therefore the time of getting information of coming natural or socially-constructed threat is minimal, it measured in the minutes. Thus, the first task of geo-politicians is to supply us with the instruments of quick and adequate response.

Fourth, in turn it means that a system of institutions of any scale has to be restructured and adapted to these new nonlinear, uncertain and movable conditions. 
Fifth, it also signifies that there is no absolutely safe place on the planet - there are more or less safe only, and everybody should look for safe place individually. Such process of individualization of humans means that our world is becoming less organized and more chaotic.

Sixth, in the above conditions a modern education system should include a set of practical skills of individual and group defense.

Finally, under such conditions the geopolitics is becoming a dictatorship replacing any forms of democracy. Such perspective means that substantial transformation of international social order is needed.

\section{The main features and difficulties of current transition process}

To begin with, the current transition toward a digital age of every social community or society including Russia means its inclusion in the ongoing global transition process, not only geopolitical one but in a couple of transformations going in various directions with different pace. In Russia, in particular, one can see a substantial break between the advanced ITresearch and technologies that developing in line with the most advance countries and substantially backward industrial technologies In particular, the author cited J. Friedman, the director of the Stratfor Company (the World's Leading Geopolitical Intelligence Platform) who predicted that Russia couldn't to manage with its geo-economic role (cited by: Malinetsky, 2019: 04). In any case the gap between the IT-industry and other branches of Russian heavy industry is one of the features of state of affairs that should be surmounted in the coming transition period.

But as the President V. Putin said, 'The ongoing changes have civilizational character, and the scale of this challenge urges us for the strong response to it.' It means that it's going on about the necessity of all-embracing transformations of Russian society, and this statement is related to many other states and societies that want to be the active participants of shaping of a new world civilization.

The above thesis means that our society has to make the 'multiple shift': to modernize the existed heavy industry and communication systems, to reorganize secondary and the higher education, to raise the living standards, and to develop a concept of Russia's adaptation to already existed 'Internet galaxy.' As the city planner in the past, I'd add one more shift: to make the life of ordinary people more safe in the widest sense of the world (better medical services, to lessen the chemicalization of food staffs, etc.). The safety is demand which peculiar to a majority of the settlements around the world.

I see several impediments for the above transformations. First, it's a resistance of a bureaucratic system of any society that afraid to loss its profit gained from all other layers of a given society. Second, it's a threat of destruction of his/her safety net of habitual human ties and communications. It's a real risk under conditions of total informatization and robotization. Third, it's a risk of extreme alienation in depersonalized society.

\section{Environmental aspects of global geopolitics}

All recent social institutions and their agents are now included into the global SBT-system irrespectively of their national belonging. Therefore, the methodological approaches to this issue like 'nature-society' dichotomy, nature protection or nature conservation are not the adequate instruments for the study of global (or cosmic) structure and dynamics, that is of the relationships inside the global SBT-system. 
So as it has been pointed out earlier, not the biological but the interdisciplinary model of global turnover is needed. The global and cosmic metabolisms especially in space and time are investigated insufficiently because the all social agents (power, business and humans) are still behave as the masters of a wild nature. Accordingly, the natural disasters, man-made catastrophes, climatic changes, cyberattacks and other human-induced critical situations are usually considered as the 'unpleasant events' that have a temporary character. Thus, the metabolic structures and processes within global and cosmic systems should be the subject matter of contemporary global geopolitics.

Starting from this point of departure, I'll try to clarify some conceptual ideas that seem to me important here.

First, the global SBT-system is simultaneously the environment and a giant multisided agent of social and geopolitical activity. That is, the global SBT-system is a subject-object hybrid with his own space-time rhythms. Until now, the scientists and scholars have focused their geopolitical studies on mans' activity but now it's a time to investigate an integrated behavior of this subject-object hybrid.

Second, the global SBT-environment is a battlefield for natural resources. But till now a consumption of natural resources and production and dissemination of the wastes are usually analyzed separately or in local cases only. We, the scientists and practitioners should to overcome this division.

Third, another division that should be overcome is the institutional and political separation of the linear and therefore predictable environmental transformations and the critical ones which we consider as sudden calamities. Besides, there is the third agent of the transformation in question, that is the processes which we see but not able to regulate (say, the thawing of the Arctic glaciers).

Fourth, the world is on the eve of the hybrid wars which use a variety of biological phenomena as an arm. They maybe of two kinds: naturally induced like a locust attack and artificiallyconstructed in the labs as some viruses which then purposefully disseminated.

Fifth, under the umbrella of the Internet Galaxy any social entity including the individuals lives in two interrelated environments, a material and virtual ones. They are not equal: nowadays the further the more the virtual milieu dominates over the material one and the people accustomed to trust to the messages which the Internet Galaxy produced. It means that we are still living, according to U. Beck, in the environment of 'side effects.' And current environmental politics follow it.

Sixth, but modern environmental politics and global geopolitics at large should have a warning character. And so humanity is needed in a forecasting researches and strategical i.e. outstripping developments. Accordingly, any environmental politics and geopolitics at large have to be substantially retuned for such outstripping.

Seventh, a social ecology issue as a theory and practice deserves special attention. To my mind, recently any socio-ecological organism has to be analyzed and built at least simultaneously on three levels: global (or cosmic), state and local levels and the last include an individual one. All these levels have complex i.e. the SBT structure. A degree of inclusion of a particular agent in one or in all levels is a crucial question here. As I said above, any inclusion presupposes the direct and feedback networks. 
Eighth, the sociologists and other humanitarians have to give particular attention to social ecosystems. Willingly or unwillingly all particular social agents are built in a global or cosmic social ecosystem. It means that they are living not only in material and virtual worlds but in an environment of permanent struggle of particular agents for deficit resources and geopolitical domination.

Ninth, who could be a leader capable to make our world more peaceful and friendly? My answer is definite: the scientists-turned-ecoactivists only! World history and my own longterm research in this field allow me to make this statement (see, for example, Yanitsky, 2005, 2009,2010 ). This statement is supported by the data related to the recent trends in current Green movement. The activity of very small environmental group the 'Rivers without Boundaries' (the RwB) localized in the margin between China and Russia has in essence global character because it follows and analyzes the China's transboundary project 'The New Silky Road.' Later on, beginning from estimation of this project the RwB group soon shifted to the analysis of global energetic interconnection project (Shkraduk and Simonov, 2018; see also: Nabieva, 2019). These works clearly showed that the role of natural communications (the seas, rivers, and roads) isn't diminished despite the shaping united informational space.

Tenth, the previous statement needs more developed substantiation. First of all, civic society activists are simultaneously free from the institutional frames and so they are more flexible and mobile. Then, they may move forward new ideas and discuss them in various professional and civic circles. After then, they are more mobile and therefore well informed about particular cases. Finally, the scientists-turned-activists may function as insiders in various critical situations.

Eleventh, the mass-media plays an important role in conceptualization and estimation of particular decisions, projects and critical events. But their views and estimations are never socially and politically neutral. On the contrary, the media and first of all state media are aimed at the shaping of public consciousness. As a rule, social networks are more democratic.

Twelfth, a global mobility of people, goods, information is speeding up, and a 'mobile individual' feels himself lost in this unlimited and movable space. In turn, it makes him/her disoriented and uprooted losing ties with the Motherland and national culture heritage. National cultural artifacts begin to serve the tourists and other temporary visitors.

Finally, it seems to me that humanity is needed in the institute of global memory. There are a lot of institutions of national memory. Not the memory as the collections of memoires and artifacts but a kind of an archeology of evolution of global SBT-system and simultaneously of human perception and comprehension of this evolution and its modelling.

\section{The stable institutional structures vs. fast and nonlinear changes}

I disagree with blind but firm belief of a majority of the sociologists in sustainability of social institutions. Human history shows the reverse process: after a severe war is coming peaceful times, the politicians began to construct rules and norms of peaceful coexistence, new international organizations are created, etc. But in parallel the other political forces carry out secret negotiations, began to shape new military alliances and unions, and so on and so forth. As we know firmly, in the very run of the WWII some of the US high-ranked diplomats had secret talks with the representatives of leaders of the German fascist regime.

Therefore, I deeply convinced that in such realm as the global geopolitics any firm rules of games couldn't exist because of permanently coming flow of social and technical innovations. 
They will be created by two competing agents: a science and technical innovations, on the one hand, and by steady growing corps of a bureaucratic machine, on the other side. Besides, it will be limited access to financial and other resources that may provoke resource wars.

Then, a process of development of the very sphere of the IT-production will put its own set of demands, rules and norms. After then, a social sphere as such becoming more diverse and movable will require the substantial transformations of the institutions that regulate its relationships with other spheres of social life as well as with technical i.e. built and natural environment. And who will be the creator of permanently changing and/or renewing system of norms, rules, codes, protocols and other instruments of a governance of a new reality. The only one case of mass production of the cars without drivers will requires a total restructuring of the logistics and city governance.

One more source of geopolitical tensions in the Internet as such. The Internet 'machine' is already generated its own social and technical institutions, organizational structures and rules of games that are qualitatively differ from the existing ones. The very global network structure is already became the social institution with its own norms and regularities. And these quickly developing institutional sphere lags far behind from existed political norms and institutions. As the result, the conflict between existing ethical systems like the Hippocratic Oath and permanently changing medical protocols will grow. Another well-known case is the permanent international disagreements concerning disputable territories like the Golan Heights.

In sum, I foresee that the transition period in question will have complicated, unstable and conflicting in character. I also think that the existing system of international, national and community institutions will be replaced by periodically devised temporary agreements, instructions, and roadmaps. In any case, the transition period will be burdened by various conflicts, hackers' attacks, and hybrid wars, the conflicts aggravated by the growing deficit of various resources ranging from providing mass of people with drinking water and food-stuffs till lack of means and resources for nature protection, social security and safeguarding of peace and human safety.

\section{Global social ecosystems in a digital age}

As D. Stokols argued, a 'basic assumption in all branches of ecology is that organisms' encounters with their surroundings are influenced by contextual factors...In human communities, people's reactions to high population density are influenced by cultural norms for dealing with crowding in public and private places (Stokols, 2018: 50). Stokols underlined that the 'Social ecology is inherently transdisciplinary in its approach to understanding people's relationships with their surroundings. It draws on concepts, theories, and methods from several fields and emphasizes an action research orientation by integrating academic and nonacademic perspectives to more effectively analyze and manage complex societal problems.' I fully agree with his statement that the 'distinctive features of ecological research-especially its interdisciplinary, multilevel, multimethod, system-oriented, translational approach-are common to the various schools of ecology...'

But the further, his suggestion to divide the context into four environmental spheres-natural environment, built environment, socio-cultural environment, and virtual environment-poses some questions (Stokols, 2018: 66,67). First, all these spheres have been always and much more recently are highly interdepended and therefore integrated into an inseparable wholeness. Second, the same may be stated in relation to the context, it is a complex and mobile whole. Third, under various conditions the above 'spheres' if they are actually exist will play different roles in shaping the interests and forms of a particular community development 
as well as will exert different influence on the way of life, dynamic stereotypes and on the attitudes of its inhabitants toward an 'outer world.' Fourth, a very social-functional organization of a particular socioecological entity has a strong impact on the behavior of its inhabitants.

Fifth, every environment has its own carrying capacity, and if it is surmounted, this environment turns into numerous agents (actors) who are capable to undermine the wholeness of a particular community. Sixth, any human community is a SBT-system that is an integrated complexity that behaves as a 'collective actor.' But if the outside pressure continued to grow such community is destroying with emanation of giant masses of energy of decay (the refugees, involuntary migrants, emanation of toxic wastes, etc.). Seventh, recently our internet galaxy is simultaneously the context, environment and a community in which we are living in (Yanitsky, 2016). However, by and large humanity permanently expands its living environment both up, into the atmosphere and cosmic space and down into the lithosphere and the mantle of our planet.

In turn, it means that we are now living in permanently widening environment, and so it has no definite space-time margins. This very point is crucial for the comprehension and reflection concerning man-environment relationships. Reflection of everybody, be it the scientists, scholars, politicians and environmentalists.

From the viewpoint of these permanently transforming and widening processes of global SBTsystem expansion, it would be more correct to study socio-ecological communities in the frame of a triple coordinates namely their past, current state and a foreseeable future. Of course, for current practical needs the researchers and politicians may focus on a particular network structure, say, for example, on the peoples' relationships in a given community or on energy flows. But even in such cases an uncertainty of structures and processes in question is remains. The uncertainty in all dimensions: spatial, temporal, environmental as such, and in the sense of the relationships of a given subject-object with the micro and macro worlds. It's a very difficult methodological task but it correspond to the process of permanent multiplication of the expanding Big World in which we are all live in.

The geopolitics and sociologists have well mastered the Big Data methods of research, and it's now a time to comprehend a high complexity and mobility of our living environment. Of course, it will be again the contextual approach although in its much more developed form. One should remember that any sustainability is only a moment of permanent transformations.

\section{Global turnover of socio-natural-technical metabolism}

The scientists, geopolitics and ordinary people wish and struggling for the sustainability. But up to the early 1980s a common agreement existed that the opportunities for such unlimited growth do exist. But after the works of D. Meadows and his colleagues (Meadows et al., 1989), the positions of the scientists and scholars began to separate and to keep away. The scientists became the adherents of the limits to growth concept, the politicians insisted in stable growth of production forces and human consumption, and the sociologists and some other humanitarians remained 'in-between.'

The further the more the dispositions of the above three groups continue to diverge. After 50 years of intensive work of the above team the 40th report to the Club of Rome showed that there is no way out without the restructuring of a capitalist mode of production (Von Weizsäcker and Wijkman, 2018). The politicians (more exactly, geopolitics coupled with representatives of transnational business and mass-media) continue to maintain the idea of 
further economic grows combined with economy of energy and other resources. And the world sociological community has no solid stand on how to combine the wellbeing of world's population with the challenge of global warming and a necessity of saving resources.

In Russia one could observe the same situation. The social and geopolitical prognostics as a separate branch of social sciences is absent from the mid1970s. The developments of prospects of the scientific and technological revolution started at the same period soon declined as well. Nowadays, Russian sociologists well informed about the existing state of matters including the sphere of shaping current political processes but there are practically no investigations related to the near and remote future of Russian geopolitics (see, for example, Patrushev and Filippova, 2018).

The growing instability of global SBT-system and of all its units and networks may be considered as its response to the continued mode of keeping of the world economy and world geopolitics. This instability is often transferred into regional and global natural disasters and man-made catastrophes that, in turn, may have a cascade character in uncertain time and space.

\section{CONCLUSION}

Current global geopolitics is a very complicated web of mass contradictions built on real facts, knowledges, regularities, surmises, lies, wishes of particular interest groups and political leaders. That is it's not a science but the phenomenon very peculiar to our times that has no definite rules of games. Z. Bauman was absolutely right defining our epoch as the 'liquid times.' To my mind, recently all geopolitical processes have to be analyzed and designed as if they existed in the 4D space, namely width, height, length, and time. And each of these dimensions may vary from micro to cosmic scale as well as in their tempo-rhythms.

The qualitative side of global STR-4 revolution cannot be reduced to the innovations in the ITsphere. I agree with those who stated that our world is in the process of humanitariantechnological revolution. Not only technical innovations but humanitarian, economic, governmental and military technologies came to the forefront. The turn to the STR-4 is a point of bifurcation for Russia and for the global SBT-system. The upgrading of some industries and building the others is meant that our society is urgently needed in a new reform of our research and education systems. A quality of social and human potential of population is as important as the 'digital transition.'

What is a civilizational response of the abovementioned international projects? First, their participants had no idea of future geopolitics besides the threats of the planet overpopulation, deficit of resources and risks of intergovernmental or global conflicts and wars. Second, a sheer force (including hybrid wars) and not the expansion of global market have been considered as a domination form of geopolitics in this period. Third, the biosphere and the social sphere and not the cosmic space have been considered as the field of global geopolitical struggle.

Despite the Club of Rome members, the participants of Global Risks project and of the Social Ecology project have all been human-oriented in general but in particular they haven't been actually humanistic-oriented. In other words, their investigations hadn't ended with suggestions how to better a life of millions of people and to save natural ecosystems as well as our planet livable.

If the survival of the global SBT-system and of humanity is the ultimate goals of our joint efforts, the educational system including the education of geopolitics has to be substantially 
reorganized on the basis of the complex interdisciplinary knowledge and crafts. In particular, the decision-making acts should be replaced by an interrupted educational process going one step forward in comparison with actual transformations of any SBT-system. And the other people of the world have to realize that they are all the active participants of global geopolitical processes and transformations.

\section{References}

Castells M. 1996. The Information Age. Economy, Society and Culture. Oxford: Blackwell Publishers, Ltd.

Castells M. 2004. The Internet Galaxy. Reflections on the Internet, Business, and Society. Oxford: Oxford University Press.

Fisher-Kowalski M. 1997. Society's Metabolism: On the Childhood and Adolescence of a Rising Conceptual Star, in Redklift M. and G. Woodgate, eds. The International Handbook of Environmental Sociology. Northampton, MA: Edward Elgar: 119-137.

Fisher-Kowalski M. and H. Haberl. 2007. Socioecological Transitions and Global Change. Trajectories of Social Metabolism and Land Use. Vienna: Klagenfurt University.

Haberl H., Fisher-Kowalski M., Krausmann F. and Winiwater V., eds. 2016. Society-Nature Relations across Time and Space. ISBN (on-line): 978-3-319-33326-7. Available at:

http://link.springer.com/book/10.1007\%2F978-3-319-33326-7

Malinetsky G. 2019. 80 Strategies of our Mist Future. Voenno-promyshlennyi kurrier, No 10 (773): 04 (In Russ.).

Meadows D.H., Meadows D. l., Randers J.W. 1989. The Limits to Growth. A Report for the Club of Rome's Project on the Predicament of Mankind. 2nd ed. N.Y.: Universe Books.

Nabieva K. 2019. Energy Transition in South East and Eastern Europe, South Caucasus and Central Asia: Challenges, Opportunities and Best Practices on Renewable Energy and Energy Efficiency.

Available at: http://library.fes.de/pdf-files/id-moe/14922.pdf

Patrushev S. and Filippova L. 2018. The Establishment of Modern Politics in Russia: The Institutional Problems. Moscow: ROSSPEN

Shkraduk I. and Simonov E. 2018. Crossroads of the World Energy and China's Global Energy Interconnections. Technical Report. 45 pp. DOI: 10.13140/RG.2.2.21452.10855

Stokols D. 2018. Social Ecology in the Digital Age. Solving Complex Problems in a Globalized World. Univ. of California: Academic Press.

Von Weizsäcker E.U. and Wijkman A. 2018. Come On! Capitalism, Short-termism, Population, and the Destruction of the Planet. Springer. DOI 10.1007/978-1-4939-7419-1

Yablokov A., Levchenko V., Kerzhentsev A. 2015. The Decision Exists: Transition to Controlled Evolution of the Biosphere. Philosophy and Cosmology. Vol. 14: 92-118.

Yanitsky 0. 2005. Dialogue between Science and Society. Social Sciences. A Quarterly Journal of the Russian Acad. of Sciences Vol. 36, No 2: 78-90.

Yanitsky 0. 2009. The Shift of Environmental Debates in Russia, Current Sociology 57 (6): 747-766.

Yanitsky 0. 2010. Russian Environmentalism. The Yanitsky Reader. Moscow: TAUS.

Yanitsky 0. 2016. Sociobiotechnical systems: a New Approach to Man-Nature Interactions, in: Yanitsky 0. On Globalization and its Environmental Consequences. Moscow: IS RAS' pp. 123-135. Available at: http://www.isras.ru/index.php? id1198\&id=4603

Yanitsky O. 2019. Challenges and Risks of Globalization. Seven Theses. Sociologicheskiye Issledovaniya, N 1: 29-39. DOI: 10.31857/S013216250003745-2 (In Russ.). 